\title{
Improving the Efficiency of Market Information Analysis Systems using GIS, Polygon and Spatial Databases
}

\author{
Omid Izadi \\ School of Computer Science \\ The University of Nottingham, Malaysia Campus \\ 43500 Semenyih, Malaysia \\ e-mail: omid.izadi@icloud.com
}

\author{
Abdur Rakib \\ School of Computer Science \\ The University of Nottingham, Malaysia Campus \\ 43500 Semenyih, Malaysia \\ e-mail: Abdur.Rakib@nottingham.edu.my
}

\begin{abstract}
An organization's future developments are influenced by its managements' decisions. This can only happen by strengthening research and development strategies. Market monitoring and analyzing systems are designed to provide an organized flow of information to enable and support the marketing activities of an organization. In recent years the development of Market Information Analysis Systems (MIASs) to monitor and control the market has been significantly increased. However, the concept of such systems is not new and has been around for many years. Early systems were paper-based but, with the advancement of computing and information technology these systems have become more electronic and (semi) automated in nature. This paper presents a MIAS for Samsung Company in Iran which uses Geographic Information Systems (GIS), Polygon, and Spatial Databases as a component to improve the efficiency of market information analysis and monitoring systems. It also reviews the technical capabilities of GIS, Polygon, and Spatial Databases and shows how these capabilities align with accepted elements of MIAS.
\end{abstract}

Keywords-Decision Support Systems; Market Information Analysis Systems; Geographic Information Systems; Polygon, Spatial Databases.

\section{INTRODUCTION}

According to the data changes, there are a variety of views and options relating to the use of market information analysis systems. Information technology can provide a range of product concepts and can produce variety of scenarios to evaluate a marketing plan. MIAS collects the relevant data; organizes it into something meaningful, makes recommendations based on these figures and then sockets it up for future use. It consists of people, equipment, and procedures to gather, sort, analyze, evaluate, and timely distributes the accurate information to the marketing decision makers and managers.

In the literature, many researchers apply the term MIAS to sales support tools such as systems for lead and prospect tracking, telemarketing, and customer support. Others emphasize market intelligence and planning or focus on support systems. We view our system which Kimball and Stephen defined as "a formal system designed with the objective of creating an organized regular flow of relevant information for use and analysis by marketing decision makers" [1].
A good MIAS should be: a unified system; compatible with the culture and level of sophistication of the organization; user-oriented; user-friendly; involve the suppliers of the information; economical; capable of smoothly absorbing changes that become necessary; fast. It should also be conceived and used as a marketing decision system which involves users.

Most of the older versions of MIAS were developed in such a way that they generate normal reports in table, graph, or chart format. However, the new technologies which are available in these days help the system developers to improve the report generation process and its format. Furthermore, it provides much more user friendly environments to the system users.

GIS is one of the tools which can be used as a component for MIAS. It is moving from isolated, standalone, monolithic, proprietary systems working in client-server architecture to smaller web-based applications and components offering specific geo-processing functionality and transparently exchanging data among them. GIS has a lot of impacts on the business. For example, it can help a retail business locate the best site for its next store, and/or help marketers find new prospects, and/or by placing the data on a map highlights where we have many customers if we own a store. Also it gives the ability to view, understand, question, interpret, and visualize data in ways simply not possible in the rows and columns of a spreadsheet. Furthermore, with data on a map, more questions can be asked, namely where, why, and how?, all with the location information on hand. A better decision can be made with the knowledge acquired from geographical and spatial analyses [2].

Spatial databases and Polygons are needed to be integrated with GIS maps to let users enter data through the maps. Any set of data describing the semantic and spatial properties of real world phenomena is called 'Spatial Database'. The first step in the methodology is to build a spatial database containing the distribution of the landscape features of interest which consists of one or more data layers. GIS layers are represented as polygon features that are linked to channel information which is a regional database [3], [4]. Spatial database can be implemented in a GIS, in a computer-assisted design (CAD) system coupled with a database management system (DBMS), in a spatial engine accessed through an application programming interface 
(API), and sitting on top of a DBMS, in a universal (objectrelational) server with spatial extension, in a web server with spatial viewer, and so on.

In this paper, we propose a MIAS for Samsung Company in Iran which uses GIS, Polygon, and Spatial Databases as a component to improve the efficiency of market information analysis and monitoring systems. The rest of the paper is organized as follows: In section II, we discuss related works. In section III, we describe problem statement and issues. In section IV, we describe proposed system. In section $\mathrm{V}$ we discuss and justify the technologies which have been used and conclude in section VI.

\section{RELATED WORKS}

In these days, most of the businesses and companies have their own configured market analysis systems. They ask software companies to design and develop their systems according to their business process and needs. Since MIAS brings together many different kinds of data, people, equipment, and procedures to help an organization, it is very important to gather these information and equipment in a way which will help the organization to have better decision making. MIAS should not only indicate how things are going, but also why and where performance is failing to meet the plan. It is argued that organizations which use MIAS their top management, marketing, and public relations units are benefiting most effectively and that purchasing unit is benefiting least effectively from the system. The MIAS role in organizations can be operational support, decision support, and strategic support. Based on these roles that information plays in choice of decision, organizations must ensure that they have a good management information system. It is inherent to state that decision making is an integral part of any business. MIAS have been used in many industries such as agriculture, small and medium size health care organizations, tourism management in parks and protected areas, commodity exchange, flower market, home appliances, 7-Eleven stores in Japan, shareholding medicines production companies [5], [6], [7], [8]. Most of these types of systems are using normal reports which show the information by generating tables and graphs. The information they produce is difficult to analyze and use for managers.

New versions of MIAS are using new technologies which are generating reports on Google maps using GIS and also data entry via the GIS maps using polygons and spatial databases. GIS as a component of MIAS is used in urban disaster management perspective, spatial planning and environmental management in India, environmental problem solving, facilities management, locating new customers and effectively direct marketing and advertising Efforts [9], [10].

To implement data entry from GIS maps spatial databases and polygon could be better technologies to be used. These techniques have been used to implement mapping human exposure to traffic air pollution using GIS, remote sensing data, polygon based algorithms for filling regions, urban mapping methods using high-resolution digital imagery, landscape character assessment [3], [11], [12], [13], [14], [15]. However, these techniques have not yet been extensively in MIAS.

\section{PROBLEM DESCRIPTION}

The MIASs are still in their infancy, and those have been developed are often provide normal reports which are in table, chart, or graph format. These types of reports are not useful enough to have a clear understanding of the market. As business application demands, an (semi) automated system that covers multiple product categories would be tremendously useful. It is important to have a system that helps to gather and analyze the market data/information of all product categories. Also it is necessary to have close relationship with shops and branches regarding the training and merchandizing issues. The problems that most of the businesses are facing could be classified in seven major issues:

1- Have a clear understanding of customer's buying pattern is one of the main problems that businesses are facing with. Without this, they are unable to put enough concentration towards the products, management staff unable to keep track what the buying pattern that each customer buys regularly; so, businesses unable to keep themselves in competition with others.

2- Product History is another problem which businesses have. This happens because management staffs are unable to determine the market for certain products as they do not know the past sales and this might affect in decision making where they might produce in not profitable to contribute the incomes. In the end, this might lead the company go into lost profit.

3- Time consuming is one of the most common problems. In this case where management staff need to make the decision quick and fast in order to compete with other same industry companies, there might some cases happen where they unable to have a quick access to retrieve the report of each mobile phone model and brand. It may take certain time to produce it and this causes the management staff not to be able to grab the opportunity to increase the company's income.

4- Merchandizing system in which the promotion of merchandise sales as an extensive function that includes market research and development of new products.

5- Training the sellers and teaching them how to set the decor and showcases to gain customers attraction is the other major issue which needs to be solved. Also train them about the products and how they can be used to help them attract the customers and find their needs.

6- Monitoring staff activities and tasks is another issue which is in need of management control. Also monitoring the shops issues and making sure they will be solved as soon as possible. Also the company needs to monitor the billboards for advertising purposes.

7- Track and control the Shops Issues and help them to correct their problems with shelf share and any other issues they have. 
In order to address the issues mentioned above we develop a system incorporating necessary features and are discussed in the following section.

\section{PROPOSED SYSTEM}

Marketing activities are directed toward planning, promoting, and selling goods and services to satisfy the needs of customers and the objectives of the organizations; MIAS supports decision making considering these activities. It is an efficient tool which provides past, present and projected information relating to internal operations and external intelligence. To overcome the problems and issues mentioned above for Samsung Company located in Tehran in Iran, their MIAS system needs to be improved by implementing GIS reports and also let the users enter data from the GIS maps. In this way it will be easier and faster for decision makers and managers [16], [17]. The impact of GIS application is beneficial operational, tactical and strategic decision making levels due to its analytical and solution drive functions. The field of retail enhances these features to determine points of sales, retail sites, and analyze future and competitive development. It is necessary for Samsung Company to leverage the data and applications developed as part of this GIS project in their retail outlets to enable them compete, maintain and win market share. GIS as a component of MIAS provides the possibilities for a better and more organized analysis of information, which is a prerequisite for making quality decisions. It also provides a way to analyze internal or external marketing intelligence data in a format particularly suited to marketing decision making departments and the ability to integrate both internal and external marketing intelligence data to greatly improve the effectiveness of these marketing decisions. It is not only increasing market consciousness, but also facilitating decisions based on newly acquired market information. With the proposition of a methodology and mechanism, integrating data mining techniques and expert's knowledge, GIS adoption will benefit organizations in many ways including improved organizational efficiency, effectiveness and better alternatives to existing practices in the market research industry. GIS also allows retailers, and virtually any business organization, to go beyond data integration and map generation to explore relationships within a wide range of data. In GIS we need to be aware of access to data and the political economy of information, and multiple coexisting perceptions of reality and epistemologies that dominate or, alternatively, might usefully inform applications of GIS [10], [18], [19], [9].

For data entry from the GIS maps, polygon technique with spatial database is used which is a new way of overcoming the problem of time consuming procedures in MIAS. In this way users can easily choose the points on the map and enter data even for a group of them at the same time. Figure below shows the communication model for GIS with spatial database. In the subsequent subsections, we explained how Google maps are integrated with GIS visualization systems and how to enter data from GIS maps to the database.

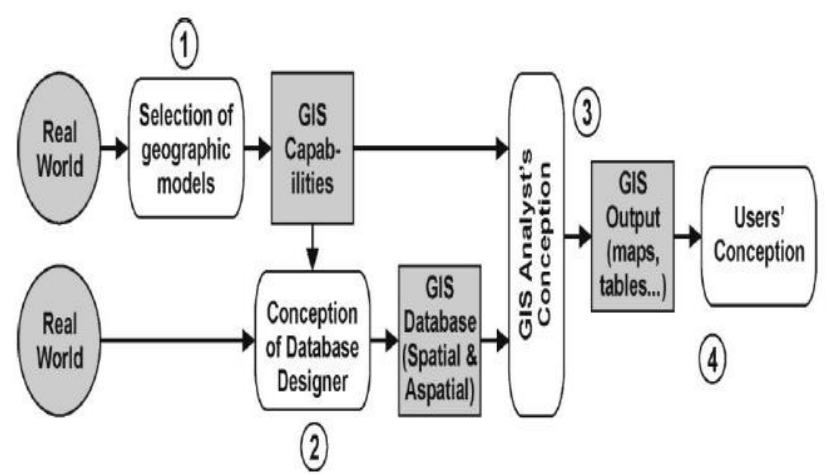

Figure 1: A model of Communication for GIS [9]

\section{A. Integrating Google Maps with GIS Visualization Systems}

Maps service is to realize the asynchronous GIS data communication between browser and a web server; it finally enhances the efficiency of program. GIS services will be implemented more extensively by using the Web Service approach. By using web services, distributed GIS services from different vendors can be dynamically integrated into the GIS applications. It includes two JavaScript class-references. One is for the Google Map object and the other is for the WMS map image and bindings to the Google Map object. For Layer-1, a classic Google mapping application is used through the AJAX web application module and XMLHttpRequest protocol. In this project, the combination of AJAX technology and Web GIS is not the same as the traditional Web GIS response to a request simultaneously, but with AJAX unique mechanism for asynchronous request, to apply to the needs of its client service and frequent interaction. Google handles creating the map by using XMLHttpRequest and given remote JavaScript file in the browser. In the application, XML describes only GIS data itself, geographical information can be configured according to the user's actual need. We use Google Maps service to disseminate geographic information. The Google Maps APIs exports a factory method for creating browser-neutral XmlHttpRequest() objects that work in recent versions of Internet Explorer, Firefox, and Safari. As with all XmlHttpRequests, any retrieved files must be on local domain. In this case, we call the method to download a static document, an XML format that contains a list of coordinates of latitude and longitude. When downloading is completed, we use GXml parsing the XML, and then polygon layer show on the map [20], [21], [22].

Figure 2 depicts how Google maps are integrated with GIS visualization system in the MIAS for Samsung Company. Here GIS technology is used to generate reports and show them on map. Under GIS reports we have two types of reports: 1- Shop Overview 2- Outdoor Overview. For example in figure 2 all the shops which are for Samsung brand and also their signboard is Samsung in Tehran are shown on GIS map with red symbols. The user interface allows different filters to be chosen for generating reports according to the decision maker choices. 


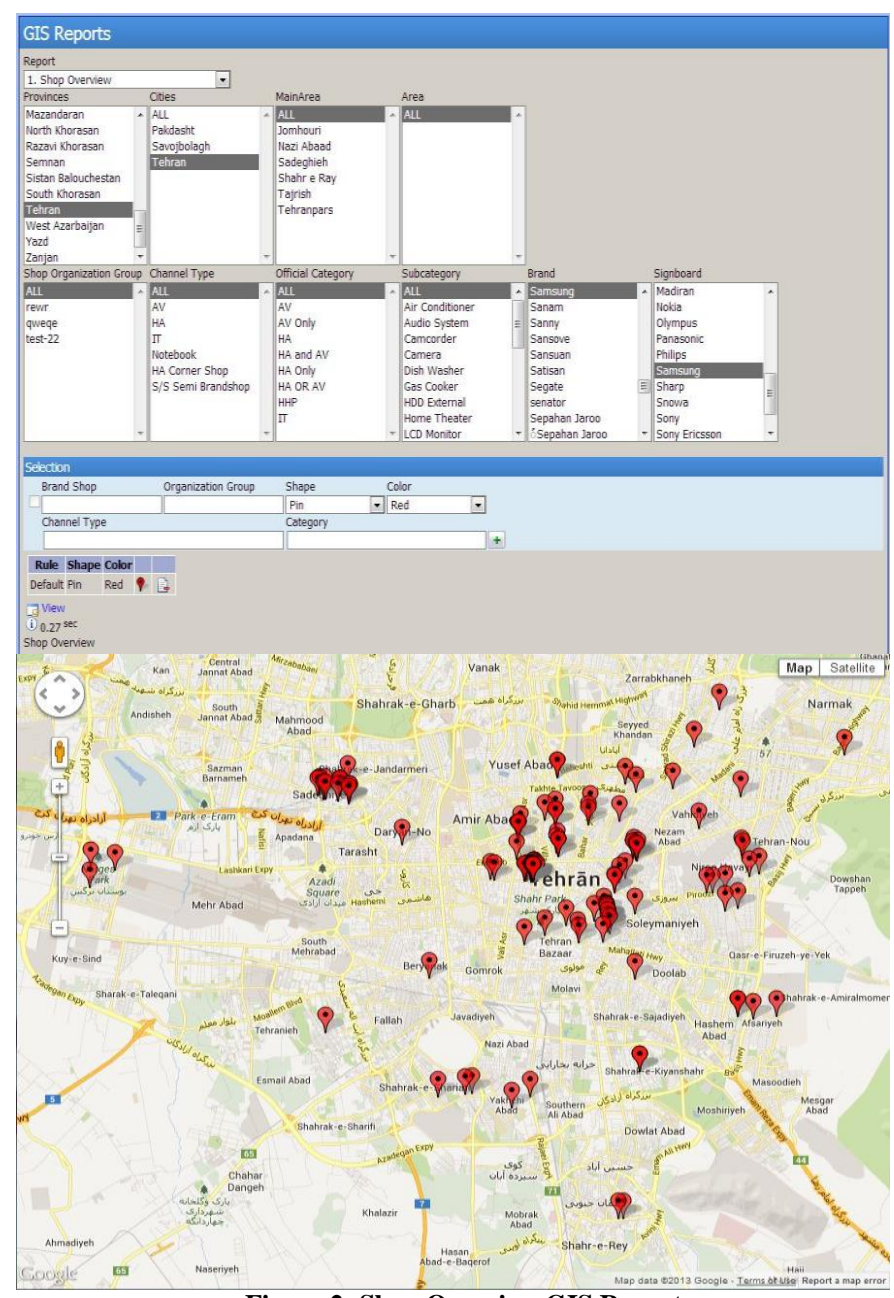

Figure 2: Shop Overview GIS Report

In figures 3 and 4 we can see that users can click on each of the red symbols to find out the details of the shops (or any other thing which the symbol is related to). Additionally, there is a "more info" option also which shows all the details. All the information about this shops visits, issues; trainings and so on are covered in this page.

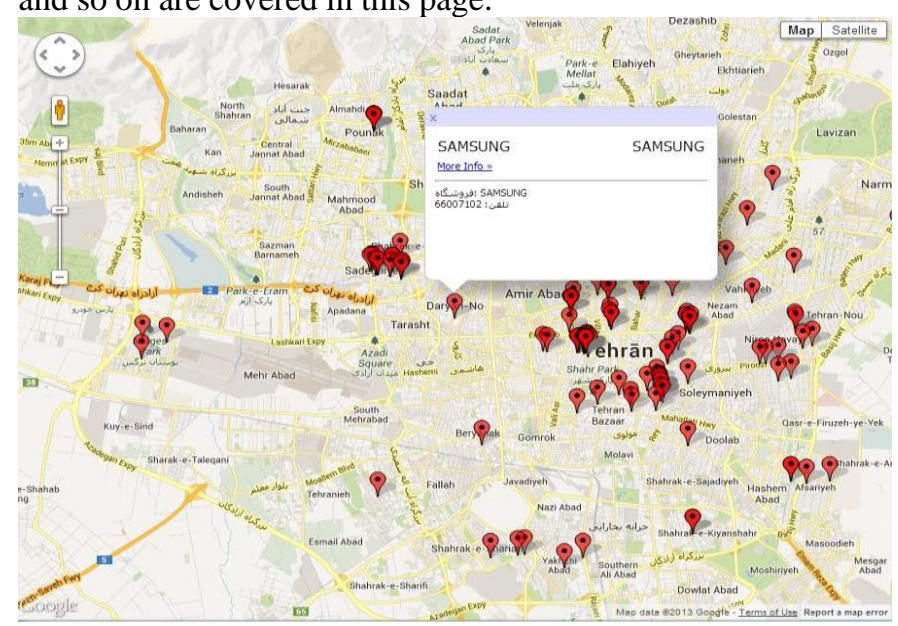

Figure 3: Symbols Information

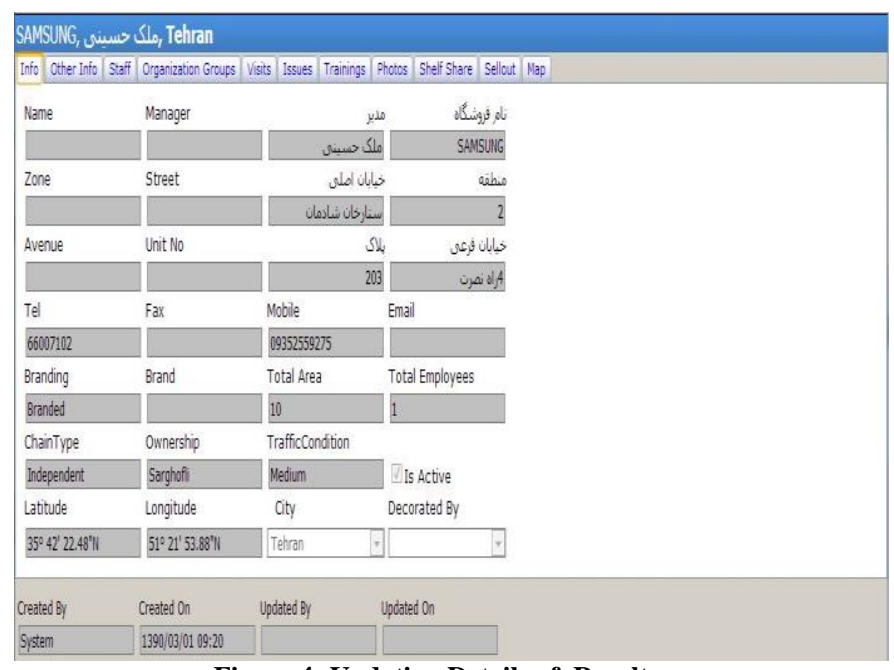

Figure 4: Updating Details of Results

\section{B. Data Entry from GIS Maps to Database}

Data in data warehouses should be structured in such a way that data can easily and intelligently be mined in order to meet real-time business needs geographically. The combination of data from multiple source applications such as sales, marketing, production and finance manifests the effectiveness of a data warehouse system. Data ware-house systems are most successful when their design aligns with the general business structure rather than specific requirements. The combination of Service Oriented Architecture and Web services can be used to provide a rapid integration solution for MIASs that are residing on legacy systems and for already existing MIASs that will not be compatible with the integration with the GIS server. The GIS server and the MIAS system can further be integrated into a service bus [10] .

Database design stage is another point which GIS production process enters (stage 2 in Figure 1). At this point decisions are made on what aspects of the real world are important to represent in a GIS database, how these aspects should be represented as spatial entities, and the determination of such things as measurement scales, categorization schemes, and frequencies of data collection. Within the bounds of what can be represented in the GIS, it should be determined that what sets of phenomena are represented as real, and how these are represented [9]. This process involved stakeholders at all four key locations in the GIS production process identified in Figure 1.

The geo-atom is the atomic form of geographic information, arguing that all geographic information can be reduced to it. For example, a polygon can be regarded as a set of atomic statements about the points constituting (or filling) the state, and a polyline defining the centerline of a street can be regarded as a set of atomic statements about points along the centerline. In both cases, the sets are in principle infinite, though we return to this issue later when we consider spatial resolution, uncertainty, and spatial autocorrelation. This discretization creates representations of fields as properties of discrete objects-polygons, triangular 
polygons, rectangular polygons, points, and polylines, respectively. However, there is an important distinction, in that the discrete objects utilized to represent a field normally have no meaning in reality but exist solely for the purposes of the representation. Moreover, the precise selection of points, lines, areas, volumes, or hyper-volumes that are created in a discretization process ultimately impacts the accuracy of the representation of any geo-field with respect to the real world. The OGC Simple Feature Specification allows in the two-dimensional planar case for multipart polygons, multipart polylines, and multipoint [23], [24]. Maintaining the source data in this way is more efficient for data storage and is easier for the user to manipulate. For instance a fertilizer treatment can easily be specified for a field as an attribute of the field feature being analyzed [4].

Locations can be polygons, such as city, county or sales territory boundaries. They also can be point features, such as customer street addresses, building locations, or vending machine locations. Or they can be linear features, such as roads, rivers, or railroads.

Figures 5 and 6 depict how users can enter data from GIS maps using polygon and spatial databases. For example, in Tehran city we search for the lampposts on which there are advertisements and are not updated since 30 days ago. The white symbols on the map are the places in which the lampposts ads are placed.

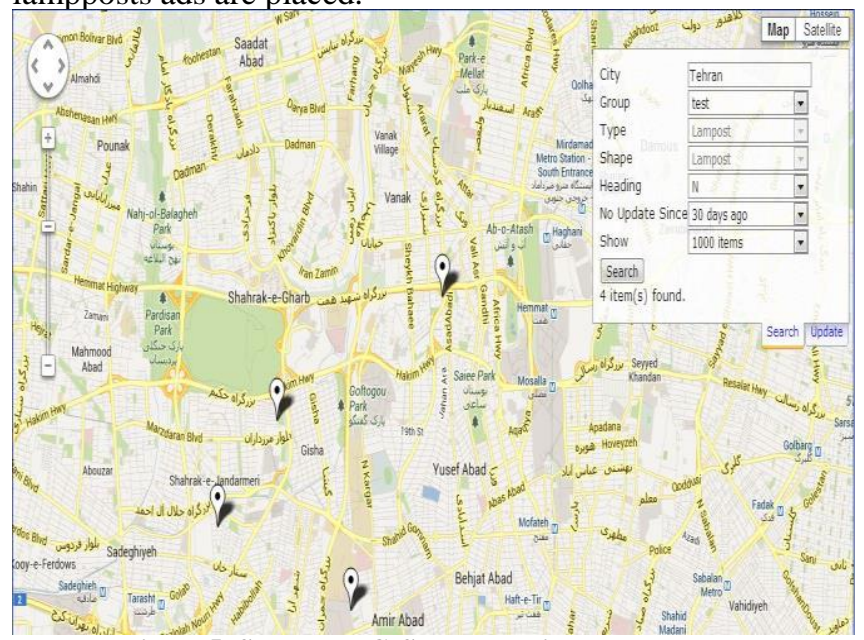

Figure 5: Search the GIS Reports with Polygon Tools

Now the user can press on the update button and changes or enters data about one or more (the color of those symbols which are selected will change to blue) of the search results and submit it to the database directly from here.

\section{DISCUSSION}

The preferred server side scripting for this project is ASP.NET. This is because ASP.NET is languageindependent that enables developer to use any of several different languages such as VB Script, Java Script, HTML, AJAX, and so on. The selected programming language for this project has been $\mathrm{C \#}$. It is intended to be a simple, modern, and fully object-oriented programming language. These specifications will help the developer in developing the dynamic website. $\mathrm{C} \#$ brings the power of $\mathrm{C}++$ with the ease of VB.NET

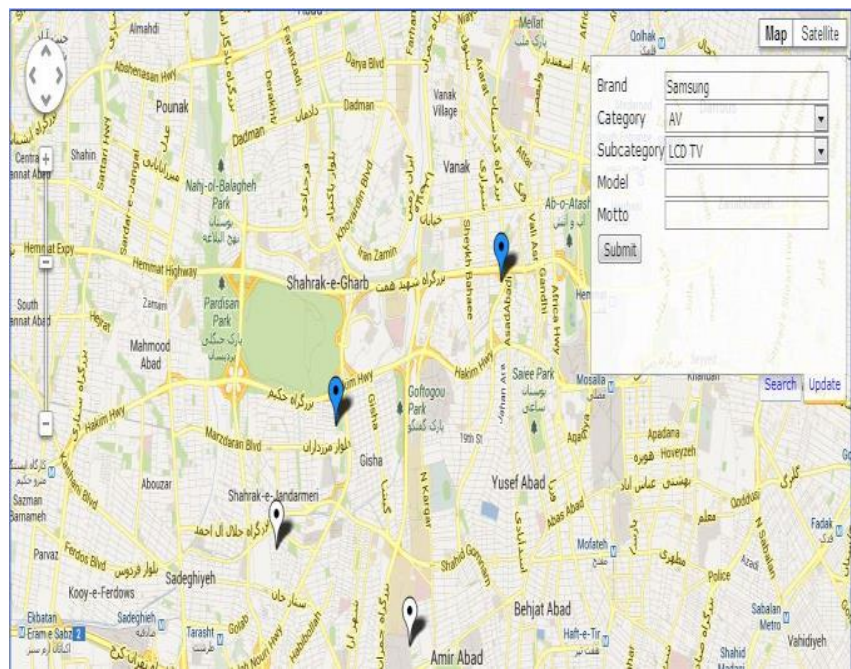

Figure 6: Data Entry and Updating from GIS Maps using Polygon and Spatial Databases

Microsoft SQL Server 2008 has been chosen as the database tool for this project because it is much easier to work with and has much better integration with .NET Framework. Also the independent platform and cheap cost are other reasons.

GIS is important for business because most business problems include significant spatial components and GIS enables decision makers to leverage their spatial data resources more effectively. This paper introduced GIS, Polygon and Spatial Database technologies as components of market information analysis systems and proposed an increased role for the technology based on the fit between the technology and elements of the marketing mix.

We accomplished this goal by presenting some of the technology's capabilities, and fundamental elements of spatial database analysis and design. Some implications of this presentation are relatively straightforward while others are subtler. With the proposition of a methodology and mechanism, integrating spatial database and polygon techniques with GIS will benefit organizations in many ways including improved organizational efficiency, effectiveness and better alternatives to existing practices in the MIAS industry.

\section{CONCLUSIONS AND FUTURE WORK}

We would like to conclude this paper by highlighting some of these implications. First, there is clearly a role for GIS in market information analysis. Second, one of the most easily realizable benefits of integrating GIS, Polygon and spatial databases into MIAS is the ability to provide mapbased presentations of data relationships for decision makers and also ability of data entry through the maps. GIS performs admirably in this role when the decision making context involves geographic relationships. Third, one of the most important capabilities of GIS is its ability to integrate disparate data using geography as the common key. Fourth, 
and less obviously, we feel that GIS and data entry through it is still in its infancy as a MIAS component. Even though the specific technology has been with us for over 20 years, the availability of end-user interfaces; personal computer, clientserver, and Internet-capable versions of GIS software; and, most importantly, widely available data and data entry from the maps are relatively recent phenomenon. In future work, we would like to enter more marketing information into computerized databases to make the needed information readily available and also use other new information technology techniques to improve the efficiency of MIASs. On the other hand, there are too much emphasis form MIAS on top management's planning activities while it is very little on low-level management's implementation activities. Low-level management are the ones who carry out the marketing plans, so more MIAS support should be shifted to them.

\section{REFERENCES}

[1] P. Kimball and W. Stephen, "Marketing Information Systems: A Marriage of Systems Analysis and Marketing Management," Journal of Applied Business Research, vol. 8, pp. 61-73, 2005.

[2] J. Venkatesh, "GIS in Indian Retail Industry - A Deliberate Tool," International Journal of Computer Science, Information Technology, \& Security, vol. 2, no. 3, 2012.

[3] U. C. Benz, P. Hofmann, G. Willhauck, I. Lingenfelder, and M. Heynen, "Multi-resolution, object-oriented fuzzy analysis of remote sensing data for GIS-ready information," ISPRS Journal of Photogrammetry and Remote Sensing, vol. 58, no. 3-4, pp. 239-258, Jan. 2004.

[4] D. Pullar and D. Springer, "Towards integrating GIS and catchment models," Environmental Modelling \& Software, vol. 15, no. 5, pp. 451-459, Jul. 2000.

[5] F. L. Cirad, G. Meijerink, and L. E. I. Wageningen, "Market information systems Using information to improve farmers' market power and farmers organizations' voice," Agrinatura Journal, 2011.

[6] R. a. Layton, "Marketing Systems A Core Macromarketing Concept," Journal of Macromarketing, vol. 27, no. 3, pp. 227242, Sep. 2007.

[7] D. J. Wade and P. F. J. Eagles, "The Use of ImportancePerformance Analysis and Market Segmentation for Tourism Management in Parks and Protected Areas," Journal of Ecotourism, vol. 2, Issue 3, pp-196-212, June 2010.

[8] S. Nowduri, "Management information systems and business decision making: review , analysis , and recommendations," Journal of Management and Marketing Research, pp. 1-8, 2011.

[9] M. Bunch, T. Kumaran, and R. Joseph, "Using GIS For Spatial Planning and Environmental Management in India," International Journal of Applied Science and Technology, vol. 2, no. 2, pp. 40-54, 2012.

[10] A. Q. Kester, "An Integrated Geographic Information System and Marketing Information System Model," International Journal of
Advanced Technology \& Engineering Research, vol. 2, no. 6, 2012.

[11] G. Camara, R. Cartaxo, M. Souza, U. M. Freitas, and J. Garrido, "Spring: Integrating Remote Sensing and GIS by Data Modeling," Computer and Graphics, vol. 20, no. 3, pp. 395-403, 1996.

[12] S. S. Jensen, "Mapping human exposure to traffic air pollution using GIS," Journal of Hazardous Materials, vol. 61, no. 1-3, pp. 385-392, Aug. 1998.

[13] H. Liu, M. Chen, S. Hsu, C. Chien, T. Kuo, and Y. Wang, "A New Polygon Based Algorithm for Filling Regions," vol. 2, no. 4, pp. 175-186, 2000.

[14] N. Thomas, C. Hendrix, and R. G. Congalton, "A Comparison of Urban Mapping Methods Using High-Resolution Digital Imagery," Photogrammetric Eng. and Remote Sensing, vol. 69, no. 9, pp. 963-972, 2003.

A. Jellema, J.C.J. Groot, and W.A.H. Rossing, "Region growing in GIS, an application for landscape character assessment," In proceedings of the Int. congress on MODSIM'07.

[16] R. Harmon, "Marketing Information Systems," Encyclopedia of Information Systems, vol. 3, pp. 137-151, 2003.

[17] G. Armstrong and P. Kotler, Marketing: An Introduction, 8th ed Upper Saddle River, New Jersey, NJ.: Pearson, Prentice-Hall, 2007.

[18] R. . Hess, R. . Rubin, and L. West, "Geographic Information System as a Marketing Information System Technology," Decision Support Systems, vol. 38, issue 2, Elsevier Science Publishers B. V., pp. 197-212, 2004.

[19] T. Moloney, "Retailers Large and Small Jump on GIS Bandwagon," Canada Computing Journal, vol. 18, no. 1, p. 26, 2012.

[20] A. Sayar, M. Pierce, and G. Fox, "Integrating AJAX approach into GIS visualization web services," Int.Conference on Internet and Web Applications and Services (AICT-ICIW'06), pp. 169169,2006

[21] X. Tan, M. Zhou, X. Zuo, and Y. Cui, "Integration WebGIS with AJAX and XML based on google maps," In proceedings of the Int. Conference on Intelligent Networks and Intelligent System pp. 376-379, Nov. 2008.

[22] G. Anderson and S. Morenol, "Building Web Based Spatial Information Solutions around Open Specifications and Open Source Software," Transactions in GIS, vol. 7, no. 4, pp. 447466, Oct. 2003.

[23] M. Egenhofer, M. Goodchild, K. Kemp, D. Mark, and E Sheppard, "Introduction to the Varenius Project," International Journal of Geographical Information Science, vol. 13, pp. 731745, 2001.

[24] M. . Goodchild, M. Yuan, and T. J. Cova, "Towards a general theory of geographic representation in GIS," International Journal of Geographical Information Science, vol. 21, no. 3, pp. 239-260, Mar. 2007. 